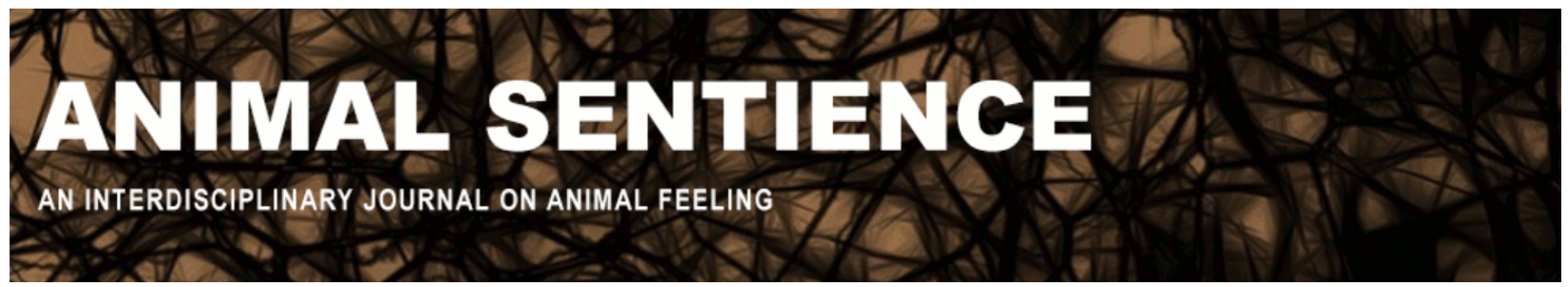

Klein, Colin and Barron, Andrew B. (2016) Insect consciousness: Commitments, conflicts and consequences. Animal Sentience 9(21)

DOI: $10.51291 / 2377-7478.1181$

Date of submission: 2016-11-22

Date of acceptance: $2016-11-28$

(c)

This article has appeared in the journal Animal

Sentience, a peer-reviewed journal on animal

cognition and feeling. It has been made open access,

free for all, by WellBeing International and deposited

in the WBI Studies Repository. For more information,

please contact

wbisr-info@wellbeingintl.org.

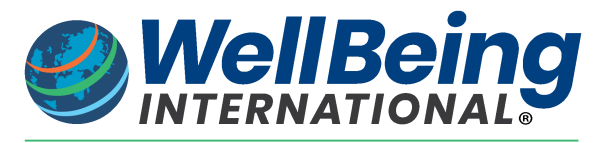

SOLUTIONS FOR PEOPLE, ANIMALS AND ENVIRONMENT 


\title{
Insect consciousness: Commitments, conflicts and consequences
}

\author{
Response to Commentary on Klein \& Barron on Insect Experience
}

\author{
Colin Klein ${ }^{1}$ \& Andrew B. Barron² \\ ${ }^{1}$ Department of Philosophy, Macquarie University \\ ${ }^{2}$ Department of Biological Sciences, Macquarie University
}

\begin{abstract}
Our target article, "Insects have the capacity for subjective experience," has provoked a diverse range of commentaries. In this response we have collated what we see as the major themes of the discussion. It is clear that we differ from some commentators in our commitments to what subjective experience is and what the midbrain is capable of. Here we clarify where we stand on those points and how our view differs from some other influential perspectives. The commentaries have highlighted the most lively areas of disagreement. We revisit here the debates surrounding whether the cortex is essential for any form of consciousness in vertebrates, how to interpret interventionist evidence, and whether any specific behavioural criteria can be used to assess the occurrence of consciousness. We recognise that these debates will not be resolved once and for all in this discussion, and we take this opportunity to explore what new forms of experimental evidence might be needed to provide clarity. We emphasise how functional neurobiological analyses in combination with careful behavioural studies of a diverse range of animals will help progress our understanding of how neural circuits can support different forms of behaviour. Ultimately this will help us reach an understanding of how different conscious capacities could be supported by neural systems, and which animals are capable of them.
\end{abstract}

Keywords: subjective experience, midbrain, hard problem, pain

\begin{abstract}
Colin Klein works on philosophy of neuroscience with a side interest in the perception of pain and other homeostatically relevant states. In 2014 he received an ARC Future Fellowship to look at interventionist approaches to cognitive neuroscience. http://www.colinklein.org
\end{abstract}

\begin{abstract}
Andrew B. Barron is exploring the neurobiology of major behavioural systems such as memory, goal-directed behaviour, and stress from a comparative and evolutionary perspective. In 2015 he was awarded an ARC Future Fellowship to develop a computational model of the honey bee brain.

http://bio.mq.edu.au/research/groups/cognitive -neuroethology/dr-andrew-barron/
\end{abstract}
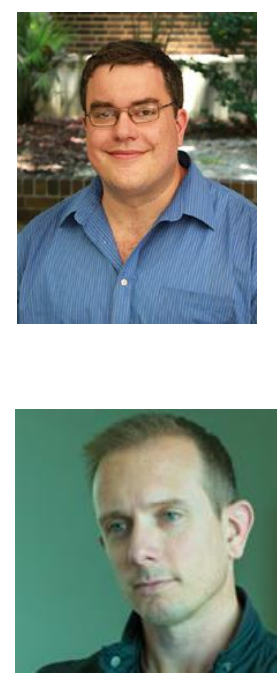

The first round of 19 commentaries on our target article (Klein \& Barron, 2016a) cover a wide range of issues and opinions. We will group our response into three categories: commitments, conflicts and consequences. 
First, there are differing opinions on what is meant by subjective experience, what is needed for it, and how it might be studied. Here we clarify what our commitments are, and how we differ from some commentators. We then turn to clear points of conflict, of which the most polarizing would be the roles of the cortex and subcortical structures in conscious experience. In responding to these points of conflict, we focus on what sorts of evidence might be needed to resolve them. Finally, some commentators have considered some hypothetical consequences if our argument is in fact correct. We spell out what we think the consequences might be, and offer some reactions to other arguments.

\section{Commitments}

Several commentators differ from us in their basic commitments. We do not know how one might settle some of these disputes, but we think it is worth clarifying what we take to be our basic commitments and why.

Subjective experience is the basal form of awareness. Our target article assumes that subjective experience is the basal form of awareness. We think that this form of subjective experience can and does occur without more complicated forms of selfreflection and self-experience. As Tye notes, this seems to be the right thing to say even about human infants, so it's not a tremendous stretch. Furthermore, we are cautiously committed to a claim that Rowlands attributes to us: we think there is some tight connection between having subjective experience and having a first-person perspective on the world. It is true that "phenomenal feel" is sometimes treated as an intrinsic property that could attach to nearly anything, but we have in mind something like Nagel's (1974) claim that "... fundamentally an organism has conscious mental states if and only if there is something that it is like to be that organism - something it is like for the organism." Conversely, and for the same reason, we think that the particular features of subjective experiences are specific to the organism that has those states, and so we are wary of requiring substantial social organization as a necessary condition (unlike van Hatteren).

Several commentators worry that the midbrain functions to which we appeal do not seem like they are sufficient for subjective experience (Adamo; Allen-Hermanson; Cruse \& Schilling; Hill; Key, 2016b). Why couldn't bees be, in Allen-Hermanson's (2008) nice turn of phrase, "natural zombies," possessing function without awareness?

Here we think that conflicting intuitions stem from two distinct sources. The first is a philosophical concern about the hard problem, and the apparent gap between the functional and the phenomenological. We have little to add here beyond the fact that we are, in Chalmers's (2003) taxonomy, committed Type-C materialists. We are unimpressed by conceivability arguments. We think that scientific advances will show where such arguments go wrong, as they have in other scientific domains.

The second source of conflict is, we suspect, an adherence to something like Lloyd Morgan's $(1894,1903)$ Canon. Why posit consciousness when you can get by with mere function? Surely, at least, the burden of proof lies, and lies heavily, on folks like us? This sort of thing reaches its rhetorical high watermark in Brian Key's (2016a) jeremiad elsewhere in this journal, where he analogizes those who posit fish pain to those who believe in Russell's celestial teapot. 
Yet Morgan's Canon has lately fallen on hard times (Andrews \& Huss, 2014; Buckner, 2013; Fitzpatrick, 2008; Mikhalevich, 2015; Sober, 2015). One strand of this debate is particularly relevant. Morgan (1903) famously suggested that:

"In no case is an animal activity to be interpreted in terms of higher psychological processes if it can be fairly interpreted in terms of processes which stand lower in the scale of psychological evolution and development." (p. 59)

Using Morgan's Canon thus not only presupposes a clear distinction between "high" and "low," but also that subjective experience falls on the "high" side of the line. We would claim that subjective experience is evolutionarily old and phylogenetically widespread. Hence appealing to Morgan's Canon simply begs the question.

Of course, lazy anthropomorphism is worth avoiding. The solution to that is evidence, not a priori reflection on what capacities might be higher or lower. Indeed, we note that Morgan updated his Canon between the 1894 and the 1903 editions to point out that postulation of "higher" processes was perfectly acceptable so long as one had "independent evidence of the occurrence of these higher processes in the animal under observation" (Morgan, 1903; Sober, 2015). We take ourselves to be providing precisely that sort of independent evidence. More generally, evidence for animal consciousness cannot be dismissed simply by claiming that consciousness is so advanced or complex or mysterious that other explanations are to be preferred if available. One might equally well run this as a modus tollens: if even insects have subjective experience, then subjective experience was not as advanced or complex or mysterious as we once thought.

Finally, and on a more conciliatory note, many commentators have pointed out the wonderful diversity of other animals that may also be conscious. While we have focused on insects, we are quite happy to see the present discussion extend to cephalopods (Mather \& Carere), decapods (Elwood), and cats (Shanahan).

The capacity of the midbrain. We begin with a few remarks on "capacity." We claim that structural features of the midbrain support the capacity to be conscious at all. Attention to the content/capacity distinction also removes another potentially misleading formulation. Several commentators took us to be saying that the midbrain/diencephalon alone is sufficient for conscious experience (Adamo; AllenHermanson; Cruse \& Schilling; Hill; Key, 2016b). This is a complex issue. Strictly speaking, our claim is only about the capacity for subjective experience. Whether that capacity is actualized in any particular case, and what the resulting contents of subjective experience end up being, may depend on many different brain structures. The important claim is that since there is no (fundamental) difference between humans and insects in the type of functional processing that occurs, there cannot be any difference in whether they have the capacity for subjective experience.

An important piece of our evidence for this claim is evidence about the effect of direct interventions on the capacity for subjective experience in individual humans (Barron \& Klein, 2016; Merker, 2007, 2013). That is one reason we have focused on natural and experimental interventions in humans. It is also why we have been impressed (as 
Merker, 2007, and Penfield \& Rasmussen, 1959, were before us) with the relative insensitivity of the capacity for subjective experience to cortical damage compared to the profound effects of subcortical damage. One might take issue with our interpretation of those results, of course. We consider those objections in the next section.

We do not claim that it is impossible for cortical damage to eliminate subjective experience - just that insofar as it does, it does so because of its effects on subcortical structures. While we do (cautiously) endorse Merker's (2007) claim that consciousness in humans is possible without a cerebral cortex, this is not a necessary commitment. It may be (as Mallat \& Feinberg suggest) that in humans the neocortex has become important secondarily for generating conscious contents, taking on functions ancestrally supported subcortically, hence one cannot have completely contentless awareness (Mallatt \& Feinberg). Here there is much room for debate, as there is for debate over which parts of the midbrain are most important.

We also make a specific set of claims about the functional processing of the midbrain that make it the basis for the capacity for subjective experience. It is widely assumed, including by many of our commentators (Chalmers, 1996; Edelman, Moyal, \& Fekete; Fekete \& Edelman, 2011), that the proper way to describe the capacity for subjective experience will be in functional or computational terms, rather than in basic neural or molecular terms. Chief among these functional capacities is the ability to integrate information about the sensory, homeostatic and motor processing of the organism into a single unified model (Merker, 2007, 2013).

We do continue to insist, however, that whatever function is appealed to ought to be tied relatively closely to specific biologically based problems and their solution in evolutionary history. The fundamental features we have appealed to are ones that arise when biological organisms begin moving around their environment under their own control (Merker, 2005, 2007). We note that other authors who are in broad agreement have emphasized a different set of functions: Eva Jablonska and colleagues emphasize the role of unlimited associative learning (Ginsburg \& Jablonka, 2015). Morsella \& Walker's Passive Frame theory (Morsella, Godwin, Jantz, Krieger, \& Gazzaley, 2015) similarly focuses on action selection in the sense of constraining output to skeletal muscle; with suitable adaptation this might be an interesting parallel. Similarly, although we assumed that Global Workspace Theory would require unreasonably sophisticated functioning, Shanahan's discussion suggests some interesting points of convergence. We welcome these discussions, and do not take them to be conflicts per se but rather the sort of conversation we hoped to open.

\section{Conflicts}

This set of commentaries has highlighted the most vigorous areas of disagreement around our target article. Clearly we won't resolve disagreements once and for all here. A better question might be: what new evidence would we need to resolve them?

Neuroanatomy: Are subcortical structures sufficient to support a capacity for subjective experience, or is the cortex essential? This is perhaps the most critical point of disagreement. We follow Merker (2005) in that we believe the processing within the structures of the midbrain, basal ganglia and diencephalon are sufficient for 
the basic capacity of subjective experience, given our commitments above. Some commentators broadly agree with us (Mallat \& Feinberg; Merker). We particularly acknowledge the contributions of Mallat \& Feinberg who published in parallel to our original paper an excellent book detailing a careful functional neuroanatomical and phylogenetic analysis of the vertebrates (Feinberg \& Mallatt, 2016). They have independently reached conclusions broadly similar to ours.

Others strongly disagree with us on this issue (Allen-Hermanson; Key, 2016b), and it seems clear that the debate cannot be settled using just the evidence currently available to us. What then would we need to give clarity? Here we agree with Key (2016b) that to make progress we need far more detailed functional and computational analyses of the brains of diverse animals. These data are coming, as connectomic initiatives and computational modelling of neural systems advance. Our argument relies heavily on functional analogies drawn across animal lineages. These analogies will be more accurate once we have more information on the forms of computation that can be supported by the brains of different animals. To understand the roles of the cortex and subcortical structures, we need more of this kind of data from within the vertebrate lineage as well as across other phyla.

(Key, 2016b) argues "that a phenomenally conscious nervous system must have observer neural networks that are able to introspect and create meta-representations of its sensory neural processing." We are not so sure about this. An "observer neural network" runs close to repackaging the philosophically difficult Cartesian theatre, or the unhelpful concept of the "brain within the brain," which we are not fond of. The concept of "meta-representations" is also not a particularly clean one. If meta-representations are simply higher order statistical summaries of sensory data, or recurrent neural networks, then insects have these. Intrinsic neurons of the insect antennal and visual lobes generate statistical summaries of sensory information to improve recognition and classification of salient stimuli (Galizia, 2014; Horridge, 2005). Recurrent neural networks and neuromodulatory elements feed back from integrative centers of the insect brain to the sensory lobes to facilitate learning of likes and dislikes ("affect" in the sense of Feinberg and Mallatt, 2016), and support the emotion-like behavioural changes recently reported for honey bees (Perry, Baciadonna, \& Chittka, 2016). We are not sure that Key would consider these kinds of meta-representations as adding to the evidence that the insect brain can support subjective experience, however. Even so, exploring the relationships between meta-representations in nervous systems and subjective experience will certainly help to bring clarity to this debate, and this is where the perspective of computational modelling is especially needed.

The role of the vertebrate cortex - interpretation of interventionist evidence. Our interpretation of anaesthesia and vegetative state studies is challenged by AllenHermanson, who notes that although we cite both Schiff (2010) and Långsjö et al. (2012), these both make reference to a cortical contribution. Allen-Hermanson notes that Långsjö et al. claim that "minimal cortical activity is necessary" for conscious experience. It would have been worth quoting the relevant Långsjö et al. passage in full, however:

"As shown in our results, only minimal cortical activity is necessary at this point. Thus, emergence of a conscious state, the essential foundation of consciousness (Fig. 
1), precedes the full recovery of neocortical processing required for rich conscious experiences." (p. 4940)

One would have thought the qualifiers were rather important, and indeed a look at Långsjö et al.'s (2012) Figure 1 confirms that there is very little activation at all outside the anterior cingulate cortex (ACC). The ACC is also the only cortical area cited by Schiff (2010), and then only because "it receives strong inputs for the anterior intralaminar nuclei" and "very diffuse regulatory input across large territories of the rostral striatum" - in short, because of its causal relationship to midbrain structures. Unilateral lesions to ACC aren't traditionally associated with loss of consciousness but with disorders of affective regulation (Bush, Luu, \& Posner, 2000). Bilateral lesions can produce akinetic mutism, but there is substantial evidence that akinetic mute patients are still conscious (Klein, Forthcoming).

Several commentators (Allen-Hermanson; Paul \& Mendl) mentioned blindsight as a possible counterexample. Here we think there is some confusion about our position. We have consistently emphasized that the cortex has an important role in shaping the contents of human experience. It is no surprise that damage to visual cortex removes whole categories of visual experience. The interpretation of blindsight cases is complicated by ongoing debates over whether there is a real distinction between Type 1 and Type 2 blindsight (Overgaard, Fehl, Mouridsen, Bergholt, \& Cleeremans, 2008; Overgaard \& Mogensen, 2015). As McPherson (2015) notes, it is also unclear what would count as distinctively visual phenomenology: if motion and form (for example) can be perceived in the absence of color and edge perception, then Type 2 blindsight might be more interpretable. We remain neutral about whether, in humans, subcortical structures alone are sufficient for any particular visual experience (rather than the capacity to have visual experience at all).

Finally, we note again that the question of how to interpret the evidence from cortical lesion studies (Allen-Hermanson) is separate from whether animals lacking a cortex might be capable of subjective experience. An animal with a cortical lesion or intervention is not the same as an animal that never had a cortex. We highlight Mallat \& Feinberg's intriguing hypothesis that the cortex might look special in higher mammals because, once it evolved, key functions supporting consciousness became far more dependent upon the cortex than on subcortical structures. This is worth exploring; functional analyses of the brains of a good phylogenetic spread of vertebrates would be a way forward.

Behaviour: Are there key behavioural criteria for subjective experience? There is clearly a lot of disagreement over what behavioural capacities, if any, demonstrate subjective experience. Van Hatteren argues that dynamic social bonding is needed because it requires animals to engage in communication that involves transforming their state of agency and goals into communicative signals. Van Hateren proposes this transformation must be so complex it must presuppose subjective experience. We agree that complex communication of one's state of self could be indicative of forms of consciousness. There are good reasons humans care a lot about other humans' declarative reports of their sense and state of self. But as we have emphasized, we do not feel this sort of behavioural evidence is necessary for the existence of subjective experience. 
Tye proposes that evidence of meta-cognition would show an animal is conscious of the things it is meta-cognizing about, but he also imagines that an animal could be capable of basic subjective awareness without being able to demonstrate meta-cognitive abilities. We are cautious about meta-cognition as evidence for any particular level of consciousness. We have been able to show that honey bees' behaviour in a choice task is influenced by their internal state of uncertainty about the correct choice (Perry \& Barron, 2013). Bees were trained in a visual discrimination task in which they received reward for a correct choice, quinine for an incorrect choice, or could simply exit the trial (opt-out). Opting out improved bees' performance overall - especially when the discrimination task was difficult (Perry \& Barron, 2013). This is interpreted as indicating that use of the opt-out was biased toward trials they were most likely to fail at. In vertebrate studies this has been interpreted as behavioural evidence of animals adjusting their choice behaviour according to their certainty of success (Crystal \& Foote, 2009; Smith, Beran, Couchman, Coutinho, \& Boomer, 2009); this meets some operational definitions of metacognitive behaviour (Dunlosky \& Metcalfe, 2009; Nelson, 1996). However, this kind of response could be achieved without a bee's having a neural representation of its state of uncertainty. This kind of behavioural response could occur if opting out is a default response when the two choices cannot be effectively distinguished and are equally attractive (Perry \& Barron, 2013).

We don't think any behavioural criteria on their own will ever differentiate animals that have subjective experience from those that don't. What are needed are careful behavioural analyses of what animals can do in combination with neurobiological analyses of how they do it. Neurobiological analyses of the scope and mechanisms of the animal brain's capacity to represent, unify, weight, value and select sensory information will allow us to make evidence-based statements about the capacity of the animal mind. Progress is already being made here. We particularly highlight the work of van Swinderen's lab (Paulk et al., 2014; van Swinderen, 2005; van Swinderen \& Greenspan, 2003) exploring the neurobiological mechanisms of selective attention in insects.

\section{Consequences}

Do insects feel pain? Several commentators focused on the question of whether insects feel pain (Elwood; Paul \& Mendl). Though pain was not part of our original argument, we do want to clarify where we stand.

The term "pain" is multiply ambiguous (Hare, 1964). In the most basic sense (what we sometimes refer to as "physical pain"), it is a sensation associated with protection of bodily integrity in the face of injury. It is thus one of many sensations associated with behaviourally mediated homeostasis (Klein, 2015), along with sensations like hunger, thirst, dyspnea, core warmth and coldness, the felt need to urinate and defecate, the hunger for specific nutrients (like sodium) and so on (Craig, 2002; Denton, 2006; Klein, 2015). All of these sensations are basic to survival, and it should not surprise us if they turn out to be widespread.

We think it is obvious that insects feel pain in this sense. Indeed, we are a bit mystified at the vehemence with which it is denied here and elsewhere given the link between pain and other homeostatic sensations. One might deny that fish are conscious at all — but 
surely if they are conscious, there is no serious debate about whether they get hungry. We suggest that a similar response is appropriate for pain. Adamo wonders what a robot might gain from feeling pain. Yet there is a perfectly straightforward story about why pain (as opposed to mere withdrawal reflexes) is adaptive. As Elwood notes for decapods, "Finely tuned decisions that weigh and trade off different motivations can be observed in decapods in response to noxious stimuli." In general, homeostatic demands are one part of the Merker (2007) triangle, broadly relevant to all actions.

Ethical consequences. Several commentators noted that our position might have profound ethical implications (Fischer; Lamey). As Fischer notes, sentience is often the criterion that separates things which don't deserve moral consideration from the things which might. Yet if insects do deserve serious moral consideration, we're in a bit of a bind. We kill unimaginable numbers of insects in the course of modern life, mostly without even trying. While our work was not motivated by ethical considerations, we are willing to follow the consequences where they lead.

The common and sensible position seems to be that if insects are conscious, then they have moral standing - in Fischer's terms, we have obligations to insects, not merely regarding insects - but that how much we owe to insects depends on what they are conscious of. This may seem like a trivial point, but it is worth emphasizing. If insects feel pain, that probably gives us more reason to care about their interests than if they just feel slightly sleepy all the time. Similarly, if there is a difference between feeling pain and suffering, then organisms that feel both arguably deserve more concern.

Clarifying what different organisms feel might then result in a gradated scale of moral duty, with insects somewhere near the bottom. Fischer suggests that the distinction between basic and sophisticated interests might provide a means for ranking. Lamey recommends traditional criteria such as psychological unity or the ability to suffer. It is also possible (though neither author emphasizes the distinction) that these criteria could be used in different ways. Insect and human standing might be comparable, in the sense that we could ask how many fleas could be killed to make a dog's life better (Lamey). Or, we might simply think that insects belong to a lower and incommensurate "tier" of moral interest, so that we should always prefer them to plants and prefer mammals to them (whatever the numbers on each side).

We are not ethicists; we leave these debates to those better suited. The important thing to emphasize is that ethical standing, on any of these accounts, depends on the contents of subjective experience. The scientific work of sorting out those contents thus remains paramount. That said, we think one point in particular is worth emphasizing. Most discussions have focused on what we might owe to individual invertebrates. This is a natural extension of human ethics, but perhaps misleading. Sentience aside, many of our moral concerns are shaped by the fact that we live long lives, and that we put relatively large amounts of resources into our children and others around us, expecting them to also live long lives. None of this translates well to invertebrates. Instead, we might think of invertebrates as something we owe duties to in aggregate. (Note that this should be distinguished sharply from a view that says that insect collectives like hives have moral standing as individuals, a position we find implausible.) That is, we may have a duty to honey bees to make sure that they don't go extinct from our pesticide usage, even if it is hard to drum up much sympathy for any particular bee. 
Evolution - why did subjective experience evolve, and how often? If it is possible to determine which animals have subjective experience and which do not, then we will be positioned to subject the trait to a phylogenetic analysis. This will show how often subjective experience has evolved, and whether (and if so how often) it has been lost. From this we will be able to infer the evolutionary circumstances that promote the evolution of subjective experience. Søvik \& Perry present a first shot at a synthesis.

We have argued above that assessing whether a species has subjective experience demands integrated behavioural, functional neurobiological and neurocomputational analyses. To draw sound phylogenetic conclusions, we will need data from a broad range of species across clades as well as sufficiently deep sampling within clades to capture diversity. Where should we start? We agree with Elwood that the crustaceans (as a sister group to insects) would be a very informative group for testing and extending our hypotheses about subjective experience in arthropods. Mollusca deserve special mention. The cognitive capacities of cephalopods are much vaunted (Mather \& Carere). But the cephalopods also sit within perhaps the most interesting comparative group. Within the extant representatives of Mollusca there is more variation in nervous system organisation, body plan and life history strategy than any other phylum. This would be an excellent group with which to elaborate a detailed comparative analysis of subjective experience.

\section{Conclusion}

While the extent to which non-human animals are conscious is hardly a new debate, we are probably the first to propose a neurobiological argument for why insects might have the capacity for a basic form of consciousness. That proposition, and these responses to it, demonstrate the rapid evolution of current thinking both about what is needed to support a capacity for consciousness and about what the insect brain is capable of.

As an indicator of how much things have changed: in 1984 Eisemann et al. characterised insect behaviour in the following way:

"By contrast, most insect behavior patterns are to a large extent pre-programmed
leaving much less scope for individual learning of appropriate behavior from
noxious and 'pleasant' stimuli, although there is a capacity for learning (including
avoidance) in both intact and decapitated insects and in isolated ganglia." (p. 165)

That view now seems very outdated. In our papers this year we have presented a model of the kinds of integrated processing we believe the insect brain is capable of, and an argument why we believe this processing is sufficient to support subjective experience (Barron \& Klein, 2016; Klein \& Barron, 2016a). We argue that both of these aspects of the thesis should be testable and refutable. Certainly functional neurobiological analyses of the insect brain are progressing at an enormous speed thanks to advances in connectomics (Chiang et al., 2011), neurogenetic technologies (Seelig \& Jayaraman, 2015) and methods of neural modeling, among other things. Our expectation is that as we learn more about how neural circuits do things and support different forms of behaviour, we will be better placed to describe what kinds of neural systems will be needed to support different forms of consciousness. We have previously proposed that 
Chalmers's "hard problem" of consciousness is hard "not because it has no answer, but because we do not yet know what a satisfying answer could look like" (Klein \& Barron, 2016b). We argue that functional analyses of diverse animal brains can help us frame an answer to the hard problem of consciousness.

\section{References}

Adamo, S. (2016). Subjective experience in insects: Definitions and other difficulties. Animal Sentience 2016.127.

Allen-Hermanson, S. (2008). Insects and the problem of simple minds: Are bees natural zombies? The Journal of Philosophy, 105(8), 389-415.

Allen-Hermanson, S. (2016). Is cortex unnnecessary. Animal Sentience 2016.113.

Andrews, K., \& Huss, B. (2014). Anthropomorphism, anthropectomy, and the null hypothesis. Biology \& Philosophy, 29(5), 711-729.

Barron, A. B., \& Klein, C. (2016). What insects can tell us about the origins of consciousness. Proceedings of the National Academy of Science of the United States of America, 113(18), 4900-4908.

Buckner, C. (2013). Morgan's Canon, meet Hume's Dictum: Avoiding anthropofabulation in cross-species comparisons. Biology \& Philosophy, 28(5), 853-871.

Bush, G., Luu, P., \& Posner, M. I. (2000). Cognitive and emotional influences in anterior cingulate cortex. Trends in Cognitive Sciences, 4(6), 215-222.

Chalmers, D. J. (1996). The Conscious Mind: In Search of a Fundamental Theory. New York: Oxford University Press.

Chalmers, D. J. (2003). Consciousness and its place in nature. In S. P. Stich \& T. A. Warfield (Eds.), Blackwell Guide to the Philosophy of Mind (pp. 102-142). Blackwell.

Chiang, A-S., Lin, C-Y., Chuang, C-C., Chang, H-M., Hsieh, C-H., Yeh, C-W., Shih, C-T., Wu, J-J., Wang, G-T., Chen, Y-C., Wu, C-C., Chen, G-Y., Ching, Y-T., Lee, P-C., Lin, C-Y., Lin, H-H., Wu, C-C., Hsu, H-W., Huang, Y-A., Chen, J-Y., Chiang, H-J., Lu, C-F., Ni, R-F., Yeh, C-Y., \& Hwang, J-K. (2011). Three-dimensional reconstruction of brain-wide wiring networks in Drosophila at single-cell resolution. Current Biology, 21(1), 1-11.

Craig, A. D. (2002). How do you feel? Interoception: The sense of the physiological condition of the body. Nature Reviews Neuroscience, 3, 655-666.

Cruse, H., \& Schilling, M. (2016). No proof for subjective experience in insects. Animal Sentience 2016.123.

Crystal, J. D., \& Foote, A. L. (2009). Metacognition in animals. Comparative Cognition \& Behavior Reviews, 4, 1-16.

Denton, D. (2006). The Primordial Emotions. New York: Oxford University Press.

Dunlosky, J., \& Metcalfe, J. (2009). Metacognition. Thousand Oaks, CA: Sage Publications, Inc.

Edelman, S., Moyal, R., \& Fekete, T. (2016). To bee or not to bee?. Animal Sentience 2016.124.

Eisemann, C. H., Jorgensen, W. K., Merritt, D. J., Rice, M. J., Cribb, B. W., Webb, P. D., \& Zalucki, M. P. (1984). Do insects feel pain? A biological view. Experientia, 40, 164-167.

Elwood, R. W. (2016). Might insects experience pain? Animal Sentience 2016.133.

Feinberg, T. E., \& Mallatt, J. M. (2016). The Ancient Origins of Consciousness: How the Brain Created Experience. Cambrige, MA: MIT Press.

Fekete, T., \& Edelman, S. (2011). Towards a computational theory of experience. Consciousness and Cognition, 20(3), 807-827. 
Fischer, B. (2016). What if Klein \& Barron are right about insect sentience? Animal Sentience 2016.115.

Fitzpatrick, S. (2008). Doing away with Morgan's Canon. Mind \& Language, 23(2), 224246.

Galizia, C. G. (2014). Olfactory coding in the insect brain: Data and conjectures. European Journal of Neuroscience, 39, 1784-1795.

Ginsburg, S., \& Jablonka, E. (2015). The teleological transitions in evolution: A Gántian view. Journal of Theoretical Biology, 381, 55-60.

Hare, R. M. (1964). Symposium: Pain and evil. Proceedings of the Aristotelian Society, Supplementary Volumes, 38, 91-124.

Hill, C. S. (2016). Insects: Still looking like zombies. Animal Sentience 2016.143.

Horridge, A. (2005). What the honeybee sees: A review of the recognition system of Apis mellifera. Physiological Entomology, 30, 2-13.

Key, B. (2016a). Burden of proof lies with proposer of celestial teapot hypothesis. Animal Sentience 2016.79.

Key, B. (2016b). Phenomenal consciousness in insects? A possible way forward. Animal Sentience 2016.132.

Klein, C. (2015). What the Body Commands: The Imperative Theory of Pain. Cambridge, MA: MIT Press.

Klein, C. (Forthcoming). Consciousness, Intention, and Command-Following in the Vegetative State. The British Journal for the Philosophy of Science.

Klein, C., \& Barron, A. B. (2016a). Insects have the capacity for subjective experience. Animal Sentience 2016.100.

Klein, C., \& Barron, A. B. (2016b). Reply to Adamo, Key et al., and Schilling and Cruse: Crawling around the hard problem of consciousness. Proceedings of the National Academy of Science of the United States of America, 113(27), E3814-E3815.

Lamey, A. (2016). Subjective experience and moral standing. Animal Sentience 2016.114.

Långsjö, J. W., Alkire, M. T., Kaskinoro, K., Hayama, H., Maksimow, A., Kaisti, K. K., Aalto, S., Aantaa, R., Jääskeläinen, S. K., Revonsu, A., \& Scheinin, H. (2012). Returning from oblivion: Imaging the neural core of consciousness. The Journal of Neuroscience, 32(14), 4935-4943.

Macpherson, F. (2015). The structure of experience, the nature of the visual, and type 2 blindsight. Consciousness and Cognition, 32, 104-128.

Mallatt, J., \& Feinberg, T. E. (2016). Insect consciousness: Fine-tuning the hypothesis. Animal Sentience 2016.118.

Mather, J. A., \& Carere, C. (2016). Cephalopods are best candidates for invertebrate consciousness. Animal Sentience 2016.107.

Merker, B. (2005). The liabilities of mobility: A selection pressure for the transition to consciousness in animal evolution. Consciousness and Cognition, 14, 89-114.

Merker, B. (2007). Consciousness without a cerebral cortex: A challenge for neuroscience and medicine. Behavioral and Brain Sciences, 30, 63-81. doi: 10.1017/S0140525X07000891.

Merker, B. (2013). The efference cascade, consciousness, and its self: Naturalizing the first person pivot of action control. Frontiers in Psychology, 4, 501.

Merker, B. (2016). Insects join the consciousness fray. Animal Sentience 2016.109.

Mikhalevich, I. (2015). Experiment and animal minds: Why the choice of the null hypothesis matters. Philosophy of Science, 82(5), 1059-1069.

Morgan, C. L. (1894). An Introduction to Comparative Psychology. London: W. Scott. 
Morgan, C. L. (1903). An Introduction to Comparative Psychology. London: The Walter Scott Publishing Company, Ltd.

Morsella, E., \& Walker, E. B. (2016). What makes us conscious is not what makes us human. Animal Sentience 2016.120.

Morsella, E., Godwin, C. A., Jantz, T. K., Krieger, S. C., \& Gazzaley, A. (2015). Homing in on consciousness in the nervous system: An action-based synthesis. Behavioral and Brain Sciences, 1-106.

Nagel, T. (1974). What is it like to be a bat? The Philosophical Review, 83(4), 435-450.

Nelson, T. O. (1996). Consciousness and metacognition. American Psychologist, 51(2), 102-116. doi: 10.1037/0003-066x.51.2.102.

Overgaard, M., \& Mogensen, J. (2015). Reconciling current approaches to blindsight. Consciousness and Cognition, 32, 33-40.

Overgaard, M., Fehl, K., Mouridsen, K., Bergholt, B., \& Cleeremans, A. (2008). Seeing without seeing? Degraded conscious vision in a blindsight patient. PLOS ONE, 3(8), e3028.

Paul, E. S., \& Mendl, M. T. (2016). If insects have phenomenal consciousness, could they suffer? Animal Sentience 2016.128.

Paulk, A. C., Stacey, J. A., Pearson, T. W. J., Taylor, G. J., Moore, R. J. D., Srinivasan, M. V., \& van Swinderen, B. (2014). Selective attention in the honeybee optic lobes precedes behavioral choices. Proceedings of the National Academy of Science of the United States of America, 111, 5006-5011.

Penfield, W., \& Rasmussen, T. (1950). The Cerebral Cortex of Man: A Clinical Study of Localization of Function. New York: Macmillan.

Perry, C. J., \& Barron, A. B. (2013). Honey bees selectively avoid difficult choices. Proceedings of the National Academy of Sciences. doi: 10.1073/pnas.1314571110.

Perry, C. J., Baciadonna, L., \& Chittka, L. (2016). Unexpected rewards induce dopaminedependent positive emotion-like state changes in bumblebees. Science, 353(6307), 1529-1531. Rowlands, M. (2016). Feel or perspective? Animal Sentience 2016.117.

Schiff, N. D. (2010). Recovery of consciousness after brain injury: A mesocircuit hypothesis. Trends in Neurosciences, 33(1), 1-9.

Seelig, J. D., \& Jayaraman, V. (2015). Neural dynamics for landmark orientation and angular path integration. Nature, 521, 186-191.

Shanahan, M. (2016). Consciousness as integrated perception, motivation, cognition, and action. Animal Sentience 2016.122.

Smith, J. D., Beran, M. J., Couchman, J. J., Coutinho, M. V. C., \& Boomer, J. B. (2009). Animal metacognition: Problems and prospects. Comparative Cognition \& Behavior Reviews, 4. doi: $10.3819 /$ ccbr.2009.40004.

Sober, E. (2015). Ockham's Razors. Cambridge: Cambridge University Press.

Søvik, E., \& Perry, C. (2016). The evolutionary history of consciousness. Animal Sentience 2016.135.

Tye, M. (2016). Are insects sentient? Animal Sentience 2016.111.

van Hateren, J. H. (2016). Insects have agency but probably not sentience because they lack social bonding. Animal Sentience 2016.108.

van Swinderen, B. (2005). The remote roots of consciousness in fruit-fly selective attention? BioEssays, 27, 321-330.

van Swinderen, B., \& Greenspan, R. J. (2003). Salience modulates 20-30 Hz brain activity in Drosophila. Nature Neuroscience, 6, 579-586. 